\title{
Multiple Carcinoma injuries of squamous cells and Queratoacantoma on vitiligo patient
}

\author{
Amanda Araújo Moura ${ }^{1}$ MD, Cleide Garbelini-Lima ${ }^{1}$ MD, Gabriela Evangelista de Almeida Magaldi ${ }^{1}$ MD, Débora Pongitori Gifoni ${ }^{1 *}$ MD, \\ Monique Freire de Santana ${ }^{2}$ MS, Dina Fabricio da Silva ${ }^{1}$ MD, Francilene Moreira Peçanha ${ }^{1}$ MD, Àlex Panizza Jalkh² MsC \\ ${ }^{1}$ Dermatology resident, Tropical Medicine Foundation - Dr Heitor Vieira Dourado. Manaus, Amazonas, Brazil. \\ ${ }^{2}$ Dermatology residency tutor, Tropical Medicine Foundation - Dr Heitor Vieira Dourado. Manaus, Amazonas, Brazil.
}

*Corresponding Author: Débora Pongitori Gifoni, Dermatology resident, National Reference Center for Sanitary Dermatology Dona Libânia, Fortaleza, Ceará, Brazil.

Received date: January 14, 2021; Accepted date: February 22, 2021; Published date: March 03, 2021

Citation: Amanda A Moura, Cleide G-Lima, Gabriela EDA Magaldi , Débora P Gifoni, Monique FD Santana, et al. (2021) Multiple Carcinoma injuries of squamous cells and Queratoacantoma on vitiligo patient. International Journal of Clinical Case Reports and Reviews. 6(4); DOI: $10.31579 / 2690-4861 / 107$

Copyright: @ 2021 Débora Pongitori Gifoni, This is an open-access article distributed under the terms of the Creative Commons Attribution License, which permits unrestricted use, distribution, and reproduction in any medium, provided the original author and source are credited.

\begin{abstract}
:
Vitiligo patients undergo a destruction of melanocytes. The melanin reduction inflicts as a risk factor for the development of skin neoplasia. Cases of malignant nonmelanocytic tumors and melanoma within the vitiligo patients is rare and isolated. This study reports the multiple injuries of the squamous cell carcinoma and keratoacanthoma within the intense vitiligo affected areas.
\end{abstract}

Keywords: carcinoma of squamous cells; ultraviolet radiation; vitiligo

\section{Introduction}

Vitiligo is a chronic degenerative pigment disease, which affects from 0,5 to $2 \%$ of the population. It presents reduction or lack of melanin and it is characterized by an uneven depigmentation of skin, mucus membrane and hair. There is no geographical limitation to the disease appearance, whereas it is identified a variable course, expressive psychological and social consequences [1].

The vitiligo patients' increase of melanocytes sensibility to the induced apoptosis by Ultraviolet B (UVB) in comparison to the normal melanocytes was linked to its altered capability to deal with the heighten of oxidative stress. It was expected that the patients developed a higher risk of early photodamage and squamous cell carcinoma. The ultraviolet radiation is the more expressive risk factor to the development of squamous cell carcinoma. However, sporadic cases of squamous cell carcinoma occurrence on vitiligo injuries may be found. There has been an increase of case report regarding the development of squamous cell carcinoma on vitiligo injuries after the extended duration phototherapy treatment, which was observed even on areas no exposure [2].

The skin which suffered depigmentation by the termination of the melanocytes and consequently reduction of melanin, which is an intrinsic skin protection factor, would result in photosensitivity to ultraviolet radiation and induction of carcinogenesis. Although, evidence shows that there is no significant heighten of melanoma risk or no-melanoma skin cancer (CPNM) on vitiligo, even if long exposure to ultraviolet radiation and ultraviolet light narrow band. The following case report shows a patient who displayed innumerous squamous cell carcinoma on vitiligo injuries.

\section{Case report}

Female, 84 years old, born at Careiro da Várzea - Amazonas, Brazil, arrived at the Dermatology Department in Manaus (Amazonas, Brazil) in August 2014, aimed to investigate nodular injury with crusted and crateriform center, fast growth within 2 months of evolution, post trauma at the anterior side of the right leg over the vitiligo injury (Figure 1). The assessment was done Wood light, which showed bright white coloring. After total exeresis of skin lesions the histopathologic confirmed the keratoacanthoma condition.

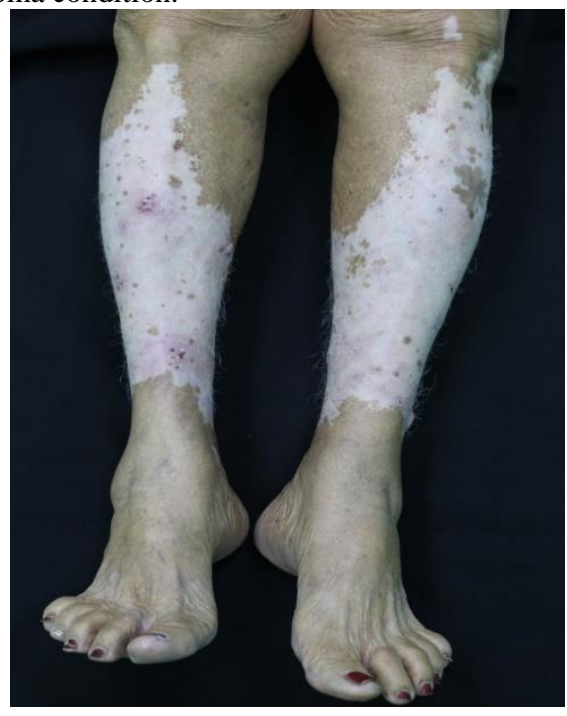

Figure 1: Nodular injury with crusted and crateriform center at the anterior side of the right leg over the vitiligo injury 
In July 2017, the patient returned showing crateriform nodular injury, erythematosus, measuring $1,3 \mathrm{~cm}$, located at the edges of vitiligo injuries on left pretibial area and nodule injuries measuring $1 \mathrm{~cm}$ on the anterior side of the right leg and $0,9 \mathrm{~cm}$ at the medial lower third of the right leg (Figure 2).

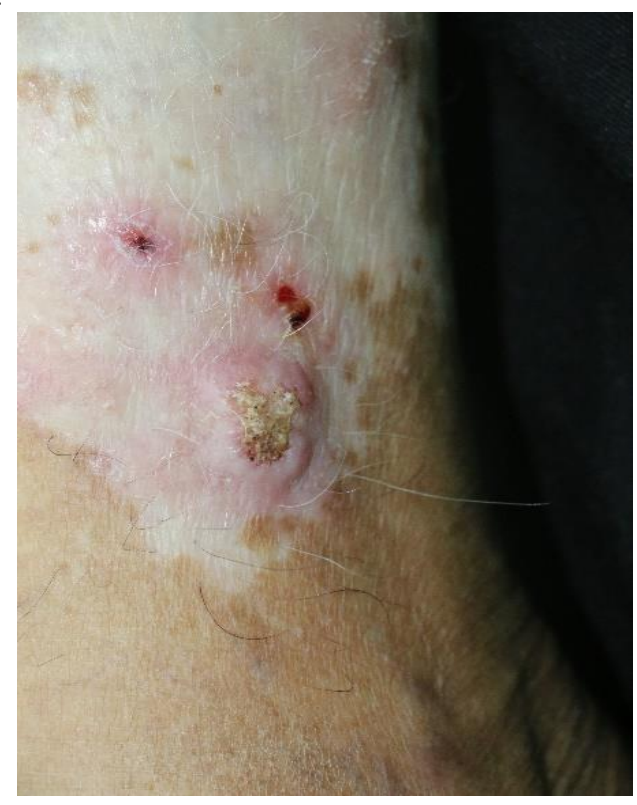

Figure 2: Crateriform nodular injury at the medial lower third of the right leg

The dermoscopy analyses of injury at the medial lower third found a hematic crust and several black spots with pink bottom shedding (Figure $3)$.

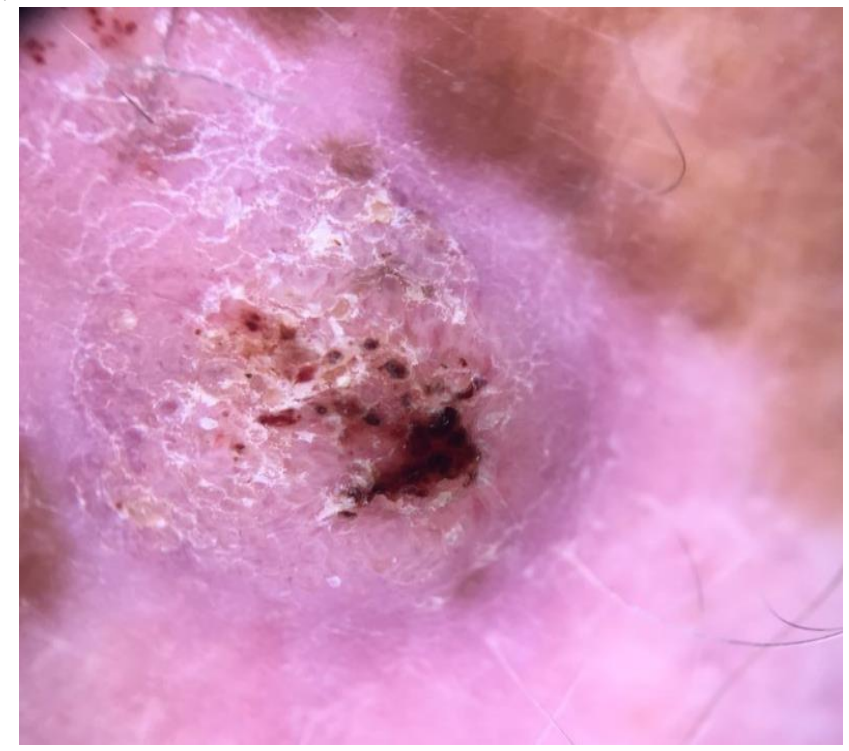

Figure 3: Scales, hematic crust and several black spots with pink bottom shedding. (Dermatoscopyl0x)

The histopathologic proved the existence of epithelial neoplasia wiht hypertrophic and hyperchromatic core, eosinophilic cytoplasm, some horny pearls formation, which caused a squamous cell carcinoma in the injury located at the pretibial portion of the left side and lower third of the right leg. The epithelial neoplasia formed by the hypertrophic core cells multiplication as well as the hyperchromatic ones with horny pearls, showed the diagnosis of a well differentiated squamous cell carcinoma
(Figure 4). All the formations mentioned showed compromising of the side and depth of the edges over the vitiligo injury displayed by the Dopa coloring for the skin interface of health skin and vitiligo area, thus it was taken to the Oncology Study Center.

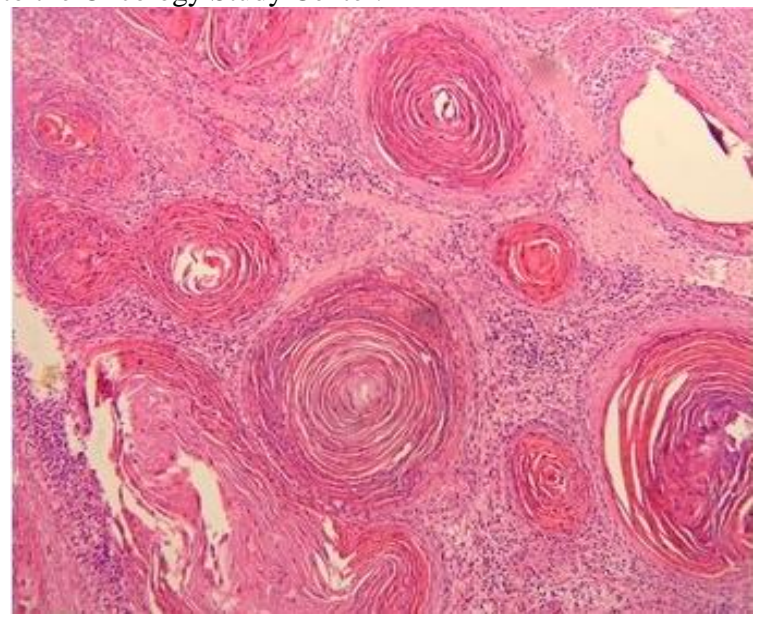

Figure 4: Hypertrophic core cells multiplication as well as the hyperchromatic ones with horny pearls (H\&E 100x)

\section{Discussion}

Vitiligo is a pigmentary skin disorder resulted by the decrease of melanocyte function. A range of melanocyte processes were affected, for instance autoimmunity, cytotoxicity, metabolic function and susceptibility genectic [3].

The ultraviolet radiation is an important risk factor to the development of squamous cell carcinoma. It is expected a more expressive risk of early photo damage and development of squamous cell carcinoma in patients who present the vitiligo because of the depigmentation and oxidative stress of skin. The Toll-Like 4 (TLRs) receptors input the ultraviolet radiation aiming to stimuli the secretion Transforming Growth Factor- $\beta$ (TGF- $\beta$ ) and Interleukin-10 (IL-10), which contribute to the photocarcinogenesis. The vitiligo has a hyper expression of Interleucina1 (IL-1), Necrosis Tumor Factor- $\alpha$ (TNF- $\alpha$ ), and reduction of TGF- $b$ and Il-10 [4].

The squamous cell carcinoma is a keratinocyte skin neoplasia that usually appear in photo exposed areas. The inefficiency and inactivation of glutation peroxidase seems to be a precocious condition for the formation of squamous cell carcinoma, since it would interact as a protector of the oxidative damage, as well as the reduction of superoxide dismutase activity, which if hyper expressed causes the omission of those neoplasias. It was found in vitiligo patients the levels of superoxide dismutase and glutation peroxidase are elevated [4].

The protection against ultraviolet radiation brought by the increase of protein p53 levels, wild type keratinocytes, through the protein levels MDM-2 and reduction of antioxidant defense function, through the decrease of enzymatic activity of thioredoxin reductase for vitiligo patients, consequently reduction of early photo damage and the appearance of CPNM [5, 6]. These facts conflicted the situation of the patient of this study, who displayed intense photo damage.

A retrospective analysis with 477 patients, whit the annual frequency of CPNM in vitiligo patients was higher than frequency in the United States [7].

Many relevant researches demonstrate the slightest risk of CPNM over vitiligo injuries. In 1998, a study analyzed 1052 vitiligo patients with no report of CPNM [8]. 
In 2002, Schallreuter et al., dated 136 white skin vitiligo patients with solar exposure in retrospective research, no signings of photo damage or CPNM were found [9]. Contrary to what is presented on this research, which the patient displayed many queratosis actinic, solar melanoses and leukoderma guttata on photoexposed areas.

In 2013, were studied 1307 vitiligo patients and found a low probability of CPNM. Was noted 2 basal cell carcinoma over the vitiligo area and no squamous cell carcinoma, which opposes to the findings reported for this case study that found 3 injuries at the area for the same condition [10].

Through a coorte study in 2014, Paradisi et al sampled 10040 people to compare the frequency of CPNM in vitiligo patients and vascular surgical patients. The range was of $3,8 \%$ of CPNM for vitiligo patients whereas $19,6 \%$ for the vascular patients [5].

The relative protection of CPNM in vitiligo patients shows strong scientific evidence of higher frequency on areas not affected by the disease. In view of this, the case presented demonstrates a rare manifestation of multiple squamous cell carcinoma injuries over vitiligo injury, reinforcing the recommendation of ample sun protection to avoid exposure to vitiliginous skin and to reduce incidental UV.

Conflict of interest: The authors affirm there are no conflict of interest.

\section{Reference}

1. Rodrigues M. (2017) Skin Cancer Risk (Nonmelanoma Skin Cancers/Melanoma) in Vitiligo Patients. Dermatol Clin.35: 129-134.

2. Gangopadhyay A, Das JK, Agarwal AK. (2014) Squamous Cell Carcinoma in a Patient with Vitiligo of Photo-covered Skin. Indian J Dermatol. 59(2): 193-194.
3. Bellei B, Pitisci A, Ottaviani M, Ludovici M, Cota C, Luzi F, et al. (2013) Vitiligo: A Possible Model of Degenerative Diseases. PLoS ONE. 8(3): e59782.

4. Feily A, Pazyar N. (2011) Why vitiligo is associated with fewer risk of skin cancer? Providing a molecular mechanism. Arch Dermatol Res.; 303:623-624.

5. Paradisi A, Tabolli S, Didona B, Sobrino L, Russo N, Abeni D. (2014) Markedly reduced incidence of melanoma and nonmelanoma skin cancer in a nonconcurrent cohort of 10,040 patients with vitiligo. J Am Acad Dermatol. 71:1110-1116.

6. Schallreuter KU, Tobin DJ, Panske A. (2002) Decreased photodamage and low incidence of non-melanoma skin cancer in 136 sun-exposed Caucasian patients with vitiligo. Dermatology. 204:194-201.

7. Hexsel CL, Eide MJ, Johnson CC, Krajenta R, Jacobsen G, Hamzavi I, et al. (2009) Incidence of nonmelanoma skin cancer in a cohort of patients with vitiligo. J Am Acad Dermatol. 60:929-933.

8. Lindelof B, Hedblad MA, Sigurgeirsson B. (1998) On the association between vitiligo and malignant melanoma. Acta Derm Venereol. 78:483-494.

9. Schallreuter KU, Tobin DJ, Panske A. (2002) Decreased photodamage and low incidence of non-melanoma skin cancer in 136 sun-exposed caucasian patients with vitiligo. Dermatology. 204:194-201.

10. Teulings HE, Overkamp M, Ceylan E, et al. (2013) Decreased risk of melanoma and nonmelanoma skin cancer in patients with vitiligo: a survey among 1307 patients and their partners. Br J Dermatol. 168:162-171.
This work is licensed under Creative Commons Attribution 4.0 License

To Submit Your Article Click Here: Submit Manuscript

DOI: $10.31579 / 2690-4861 / 107$
Ready to submit your research? Choose Auctores and benefit from:

* fast, convenient online submission

* rigorous peer review by experienced research in your field

* rapid publication on acceptance

* authors retain copyrights

* unique DOI for all articles

* immediate, unrestricted online access

At Auctores, research is always in progress.

Learn more www.auctoresonline.org/journals/international-journal-ofclinical-case-reports-and-reviews 